\title{
Determinação do índice de risco ambiental das instalações de uma unidade de uma instituição federal multicampi de ensino superior
}

\author{
Determination of the environmental risk index of the facilities of a federal multicampus institution of higher education \\ Ana Júlia Teixeira Senna', Ricardo Ribeiro Alves², Nara Rejane Zamberlan dos Santos ${ }^{3}$, \\ Fabrício Lopes Costa ${ }^{4}$
}

\author{
1, 2, 3,4 UNIPAMPA
}

\section{Resumo}

A preocupação com o desenvolvimento sustentável vem ganhando importância nas organizações públicas e privadas, dentre as quais, incluem-se as Instituições de Ensino Superior (IES). Para aquelas organizações que ainda não adotaram um Sistema de Gestão Ambiental (SGA), uma etapa preliminar é o levantamento e a análise dos aspectos e impactos ambientais. Desta forma, o objetivo deste trabalho foi realizar o Levantamento dos Aspectos e Impactos Ambientais (LAIA) de uma unidade de uma Instituição Federal Multicampi de Ensino Superior, com a utilização da ferramenta FMEA (Análise dos Modos de Falha e seus Efeitos), identificando o Índice de Risco Ambiental (IRA). A escolha por este método deu-se, basicamente, pela possibilidade de se avaliar os riscos ambientais em função da facilidade de implantação de ações corretivas gerando, desta forma, uma lista de ações a serem desenvolvidas em vários estágios de tempo, permitindo o início do planejamento de um SGA. Após a visita coletiva aos espaços, verificaram-se in loco os aspectos e impactos ambientais dos seguintes ambientes: biblioteca/sala de estudos; salas dos professores/Núcleo de Desenvolvimento Educacional (NUDE); hall e corredores; banheiros; secretaria acadêmica/administrativa e laboratórios. Através desta pesquisa foi possível constatar que a principal causa potencial dos impactos ambientais é a falta de manutenção do sistema elétrico.

Palavras-chave: : Gestão Ambiental; Índice de Risco Ambiental; FMEA; Universidade.

\begin{abstract}
The concern about sustainable development has been gaining momentum at public and private organizations, and they include Higher Education Institutions (HEI). For those organizations which have not yet adopted an Environmental Management System (SEM), a preliminary step consists in a survey and analysis of the environmental aspects and impacts. Therefore, the goal of this paper consisted in conducting a Survey of the Environmental Aspects and Impacts (SEAI) of a unit of a Federal Multicampus Institution of Higher Education, with the use of the Failures Modes and Effects Analysis (FMEA) tool, identifying the Environmental Risk Index (ERI). The choice of this method stemmed, basically, from the possibility to assess the environmental risks by virtue of the facility in implementing corrective actions, thus generating a list of actions to be developed in several time stages, allowing for beginning a SEM plan. After a collective visit to the venues, the environmental impacts and aspects of the following environments were verified on the spot: library / study hall; staff room / Educational Development Nucleus (EDN); recreation hall and corridors; restrooms; student administration services and laboratories. Through this survey it was possible to ascertain that the major potential cause of the environmental impacts is the poorly maintained electrical system.
\end{abstract}

Keywords: Environmental Management, Environmental Risk Index; FMEA, University. 


\section{INTRODUÇÃO}

A preocupação com o desenvolvimento sustentável, segundo Tauchen e Brandli (2006), vem ganhando um espaço crescente nas organizações públicas e privadas. Além disto, a responsabilidade socioambiental hoje faz parte da gestão estratégica das organizações.

O levantamento e a análise dos aspectos e impactos ambientais constitui uma das principais etapas da implementação de um Sistema de Gestão Ambiental. Essa ferramenta foi projetada inicialmente para diagnosticar as falhas em potencial em projetos novos ou modificados da indústria aeronáutica. Hoje, o método de Análise dos Modos de Falhas e seus Efeitos (FMEA) é também utilizado para diagnosticar problemas ambientais (VANDERBRANDE, 1998).

A ferramenta FMEA - Failure Mode and Effect Analysis - Análise dos Modos e Efeitos das Falhas é um método analítico para aplicar em projetos, produtos e processos, industriais ou administrativos, que serve para identificar todos os possíveis modos potenciais de falha e determinar o efeito de cada uma sobre o desempenho do sistema (ZAMBRANO E MARTINS, 2007).

Segundo Andrade e Turrioni (2000) o método FMEA permite: a identificação dos modos/causas de falhas potenciais relacionadas ao meio ambiente; a identificação das variáveis que deverão ser controladas para redução da ocorrência ou melhoria da eficácia da detecção das falhas; a classificação dos modos de falhas potenciais, estabelecendo assim, um sistema de padronização para a priorização das ações corretivo-preventivas; a documentação dos resultados ambientais. Posteriormente, a aplicação da ferramenta, deve-se analisar se as ações recomendadas diminuíram a probabilidade de ocorrência da falha. Desta forma, a constante aplicação do FMEA resultará na melhoria contínua da organização.

Para a implantação de um SGA, o primeiro passo é identificar os aspectos ambientais relativos às atividades da organização. Como a Universidade investigada ainda não possui um SGA implantado, o objetivo deste trabalho foi realizar o Levantamento dos Aspectos e Impactos Ambientais (LAIA) de uma unidade dessa Instituição Federal Multicampi de Ensino Superior, com a utilização da ferramenta FMEA (Análise dos Modos de Falha e seus Efeitos), identificando o Índice de Risco Ambiental (IRA). A determinação deste índice possibilita a elaboração de um plano de ação que vislumbre, tanto no médio e longo prazo, a melhoria contínua dos seus processos e a minimização dos impactos ambientais causados por estes.

A escolha por este método deu-se, basicamente, pela possibilidade de se avaliar os riscos ambientais, graduando-os por seus diversos aspectos impactantes e dentro das características de cada ambiente organizacional, em função da facilidade de implantação de ações corretivas gerando, desta forma, uma lista de ações a serem implantadas em vários estágios de tempo, permitindo o início do planejamento de um SGA.

\section{METODOLOGIA}

Com base nos trabalhos de Andrade e Turrioni (2000) e de Campani (2006), que analisaram a aplicação de uma ferramenta já existente para Análise de Falha e Efeitos (FMEA) foi seguido os seguintes passos:

1. Definição dos ambientes a serem considerados.

2. Visita coletiva para levantamento dos aspectos e impactos ambientais de um ambiente, como forma de uniformizar os procedimentos analíticos dos espaços.

3. Identificação dos aspectos e impactos ambientais dos demais ambientes.

4. Identificação do espaço a ser analisado. Para uma análise do FMEA mais detalhada, agrupou-se os espaços que possuíam aspectos e impactos semelhantes: biblioteca/sala de estudos; salas dos professores/NUDE; banheiros; secretarias acadêmica/administrativa e laboratórios.

5. Identificação das causas dos aspectos/impactos ambientais. Foram identificadas as causas potenciais geradoras de aspectos/impactos ambientais.

6. Identificação dos controles atuais de detecção das falhas ou causas. Levantamento das formas de controle. Foram analisadas as possibilidades de resposta à implantação das ações.

7. Atribuição dos valores dos índices de criticidade. Foram determinados os quatro índices de criticidade, conforme trabalho de Campani (2006). 
A Gravidade de Impacto (G), estima numa escala de 1 a 10 o grau de um impacto ambiental em face de sua ocorrência. O Quadro 1 apresenta as diretrizes para classificar o índice de gravidade do impacto.

Quadro 1. Diretrizes para classificar o índice de gravidade do impacto.

\begin{tabular}{|l|l|}
\hline $1-2$ & Dificilmente será visível. Muito baixa para ocasionar impacto ao ambiente. \\
\hline $3-4$ & Impacto baixo ou muito baixo ao ambiente. \\
\hline $5-6$ & Desconformidade com normas legais. Prejuízo moderado ao ambiente. \\
\hline $7-8$ & Sérios prejuízos à saúde das pessoas diretamente envolvidas nas tarefas. \\
\hline $9-10$ & Sérios riscos ao ambiente. \\
\hline
\end{tabular}

Fonte: Adaptado de Campani (2006).

A Ocorrência da Causa (O) estima numa escala de 1 a 10 a probabilidade de ocorrência de uma causa (Quadro 2).

Quadro 2. Diretrizes para classificar o índice de ocorrência da causa.

\begin{tabular}{|l|l|l|}
\hline $1-2$ & Remota & Improvável sua ocorrência. \\
\hline $3-4$ & Baixo & Pequena possibilidade de ocorrência em 1 semestre. \\
\hline $5-6$ & Moderado & Razoável probabilidade de ocorrência em 1 semestre. \\
\hline $7-8$ & Alto & Ocorrência regular. \\
\hline $9-10$ & Muito Alto & Alta probabilidade de ocorrência a cada execução da tarefa. \\
\hline
\end{tabular}

Fonte: Adaptado de Campani (2006).

O Grau de Detecção (D), conforme mostra o Quadro 3, estabelece a relação entre a detecção e a solução de uma ocorrência.

Quadro 3. Diretrizes para classificar o grau de detecção.

\begin{tabular}{|l|l|}
\hline 1 & Detecção rápida e solução rápida \\
\hline 2 & Deteção rápida e solução a médio prazo. \\
\hline 3 & Detecção a médio prazo e solução rápida \\
\hline 4 & Detecção rápida e solução a longo prazo \\
\hline 5 & Detecção a médio prazo e solução a médio prazo. \\
\hline 6 & Detecção a longo prazo e solução rápida \\
\hline 7 & Detecção a médio prazo e solução a longo prazo. \\
\hline 8 & Detecção a longo prazo e solução a médio prazo. \\
\hline 9 & Detecção a longo prazo e solução a longo prazo. \\
\hline 10 & Sem detecção e/ou sem solução. \\
\hline
\end{tabular}

Fonte: Adaptado de Campani (2006).

A Facilidade de Implantação da Ação Recomendada (F) quantifica a relação custos, recursos humanos e tempo despendidos na implantação do plano de ação. As diretrizes para classificar a facilidade de implantação da ação recomendada são apresentadas no Quadro 4. 
Quadro 4. Diretrizes para classificar a facilidade de implantação da ação recomendada.

\begin{tabular}{|c|c|c|c|}
\hline & Custo & № de Pessoas & Tempo \\
\hline 1 & \multicolumn{3}{|c|}{ Não existe tecnologia ou o custo da mesma é inviável. } \\
\hline 2 & Alto & Todas & Alto \\
\hline 3 & Alto & Apenas as envolvidas na tarefa. & Alto \\
\hline 4 & Alto & Todas & Baixo \\
\hline 5 & Alto & Apenas as envolvidas na tarefa. & Baixo \\
\hline 6 & Baixo & Todas & Alto \\
\hline 7 & Baixo & Apenas as envolvidas na tarefa. & Alto \\
\hline 8 & Baixo & Todas & Baixo \\
\hline 9 & Baixo & Apenas as envolvidas na tarefa. & Baixo \\
\hline 10 & \multicolumn{3}{|c|}{ Custo mínimo ou custo benefício de retorno imediato. } \\
\hline
\end{tabular}

Fonte: Adaptado de Campani (2006).

8. Desenvolvimento dos Planos de Ações (Ação Recomendada). Foram estipuladas ações de prevenção ou correção para sanar ou conter os aspectos e impactos ambientais.

9. Determinação do IRA - Índice de Risco Ambiental. O índice é resultante da multiplicação dos valores estimados para os quatro índices anteriores ( $\mathrm{G}, \mathrm{O}, \mathrm{D}$ e F), obtidos a partir dos Quadros 1, 2, 3 e 4. O produto da multiplicação será o Índice de Risco Ambiental (IRA), de cada aspecto ambiental. Estes índices possibilitarão uma hierarquização da relevância de cada aspecto/impacto analisado. Serão destacados como itens de prioridade para a implantação do plano de ações aqueles que obtiverem um índice mais alto, seguindo uma ordem decrescente de prioridade (Campani, 2006).

\section{RESULTADOS E DISCUSSÃO}

Após a visita coletiva aos espaços da instituição, verificaram-se in loco os aspectos e impactos ambientais dos seguintes ambientes: biblioteca/sala de estudos (Quadro 5); salas dos professores/NUDE (Quadro 6); hall e corredores (Quadro 7); banheiros (Quadro 8); secretaria acadêmica/administrativa (Quadro 9); e, laboratórios (Quadro 10).

Nos Quadros 5, 6, 7, 8, 9 e 10 estão incorporados os aspectos ambientais e impactos ambientais identificados nos ambientes analisados, suas causas potenciais de ocorrência, seus controles de verificação atuais, as ações mais indicadas pela equipe, sendo estas recomendadas aos gestores tanto no sentido preventivo quanto no sentido mitigador dos aspectos ambientais levantados e, por fim, o Índice de Risco Ambiental (IRA).

A partir da análise do Quadro 5, em relação ao ambiente biblioteca/sala de estudos verifica-se que o IRA indicou como prioridade o aspecto ambiental "consumo de energia" cujo valor obtido foi 840 , tendo como causa potencial a falta de manutenção no sistema e a ação recomendada foi implantar um plano preventivo de manutenção. 
Quadro 5. Ambiente: biblioteca / sala de estudos

\begin{tabular}{|c|c|c|c|c|c|c|c|c|c|}
\hline $\begin{array}{l}\text { Aspecto } \\
\text { ambiental }\end{array}$ & $\begin{array}{l}\text { Impacto } \\
\text { ambiental }\end{array}$ & G & $\begin{array}{c}\text { Causa } \\
\text { potencial }\end{array}$ & $\mathrm{O}$ & Controle atual & D & Ação recomendada & $\mathbf{F}$ & IRA \\
\hline \multirow{2}{*}{$\begin{array}{l}\text { Geração de } \\
\text { resíduos }\end{array}$} & \multirow{2}{*}{$\begin{array}{l}\text { Reduz a } \\
\text { possibilidade de } \\
\text { reciclagem, e/ou } \\
\text { reutilização. }\end{array}$} & \multirow{2}{*}{3} & $\begin{array}{l}\text { Falha no sistema } \\
\text { de coleta seletiva }\end{array}$ & 10 & $\begin{array}{l}\text { Monitoramento } \\
\text { visual }\end{array}$ & 1 & $\begin{array}{c}\text { Melhorar o controle; } \\
\text { aumentar a quantida- } \\
\text { de de lixeiras e melhor } \\
\text { identificá-las. }\end{array}$ & 5 & 150 \\
\hline & & & $\begin{array}{c}\text { falta de } \\
\text { conscientização } \\
\text { dos usuários }\end{array}$ & 10 & $\begin{array}{l}\text { Monitoramento } \\
\text { visual }\end{array}$ & 4 & $\begin{array}{c}\text { Ações de educação } \\
\text { ambiental e conscientização. }\end{array}$ & 6 & 720 \\
\hline \multirow{9}{*}{$\begin{array}{l}\text { Condições } \\
\text { do ambiente }\end{array}$} & \multirow{9}{*}{$\begin{array}{l}\text { Comprometimento } \\
\text { da saúde, bem-es- } \\
\text { tar e segurança dos } \\
\text { usuários. }\end{array}$} & \multirow{9}{*}{6} & $\begin{array}{l}\text { Limpeza } \\
\text { insuficiente }\end{array}$ & 5 & $\begin{array}{l}\text { Monitoramento } \\
\text { visual }\end{array}$ & 1 & $\begin{array}{c}\text { Aperfeiçoar a programação } \\
\text { das equipes de limpeza; } \\
\text { aumentar o número de } \\
\text { trabalhadores. }\end{array}$ & 9 & 270 \\
\hline & & & \multirow{2}{*}{$\begin{array}{l}\text { Ventilação } \\
\text { inadequada }\end{array}$} & \multirow[t]{2}{*}{10} & \multirow[t]{2}{*}{ Conforto térmico } & \multirow[t]{2}{*}{4} & $\begin{array}{l}\text { Ajustar a capacidade } \\
\text { em função do código de } \\
\text { edificações. }\end{array}$ & 3 & 720 \\
\hline & & & & & & & $\begin{array}{l}\text { Instalação de condicionado- } \\
\text { res de ar e exaustores. }\end{array}$ & 3 & 720 \\
\hline & & & $\begin{array}{l}\text { Iluminação } \\
\text { inadequada }\end{array}$ & 10 & $\begin{array}{l}\text { Monitoramento } \\
\text { visual }\end{array}$ & 4 & $\begin{array}{l}\text { Redimensionameto dos } \\
\text { pontos de iluminação; } \\
\text { verificação periódica; } \\
\text { substituição. }\end{array}$ & 3 & 720 \\
\hline & & & $\begin{array}{l}\text { Extintores } \\
\text { de incêndio } \\
\text { inoperantes }\end{array}$ & 10 & $\begin{array}{l}\text { Monitoramento } \\
\text { visual }\end{array}$ & 2 & $\begin{array}{l}\text { Adequar ao ppci; vistoria } \\
\text { visual periódica. }\end{array}$ & 3 & 360 \\
\hline & & & $\begin{array}{l}\text { Iluminação de } \\
\text { emergência } \\
\text { inoperante }\end{array}$ & 10 & $\begin{array}{l}\text { Monitoramento } \\
\text { visual }\end{array}$ & 2 & $\begin{array}{l}\text { Adequar ao ppci; vistoria } \\
\text { visual periódica. }\end{array}$ & 3 & 360 \\
\hline & & & Ruídos externos & 10 & $\begin{array}{l}\text { Monitoramento } \\
\text { auditivo }\end{array}$ & 4 & $\begin{array}{c}\text { Adaptação das } \\
\text { dependências para } \\
\text { supressão dos ruídos. }\end{array}$ & 2 & 480 \\
\hline & & & Acessibilidade & 4 & $\begin{array}{l}\text { Pouca ou } \\
\text { nenhuma }\end{array}$ & 2 & $\begin{array}{l}\text { Adaptação das } \\
\text { dependências para um } \\
\text { melhor atendimento. }\end{array}$ & 2 & 96 \\
\hline & & & $\begin{array}{l}\text { Depósito } \\
\text { inadequado de } \\
\text { material }\end{array}$ & 10 & $\begin{array}{l}\text { Monitoramento } \\
\text { visual }\end{array}$ & 4 & $\begin{array}{l}\text { Providenciar depósito } \\
\text { adequado. }\end{array}$ & 3 & 720 \\
\hline \multirow{2}{*}{$\begin{array}{l}\text { Bens de } \\
\text { consumo }\end{array}$} & \multirow{2}{*}{$\begin{array}{l}\text { Comprometimento } \\
\text { de recursos } \\
\text { naturais; geração } \\
\text { de resíduos }\end{array}$} & \multirow{2}{*}{3} & $\begin{array}{l}\text { Consumo } \\
\text { excessivo }\end{array}$ & 5 & $\begin{array}{l}\text { Controle de } \\
\text { estoque }\end{array}$ & 2 & $\begin{array}{c}\text { Estabelecimento de } \\
\text { processo de distribuição de } \\
\text { materiais; }\end{array}$ & 6 & 180 \\
\hline & & & $\begin{array}{c}\text { Pouca } \\
\text { conscientização }\end{array}$ & 2 & Sem controle & 4 & $\begin{array}{l}\text { Conscientização do uso } \\
\text { racional dos materiais. }\end{array}$ & 8 & 192 \\
\hline \multirow{3}{*}{$\begin{array}{l}\text { Consumo de } \\
\text { energia }\end{array}$} & \multirow{3}{*}{$\begin{array}{l}\text { Redução dos } \\
\text { recursos naturais }\end{array}$} & \multirow{3}{*}{3} & $\begin{array}{c}\text { Falta de } \\
\text { manutenção } \\
\text { no sistema }\end{array}$ & 10 & Sem controle & 4 & $\begin{array}{l}\text { Implantar plano preventivo } \\
\text { de manutenção. }\end{array}$ & 7 & 840 \\
\hline & & & $\begin{array}{l}\text { Dimensionamento } \\
\text { inadequado }\end{array}$ & 10 & Sem controle & 4 & $\begin{array}{c}\text { Avaliação do projeto elétri- } \\
\text { co e adequação à demanda } \\
\text { exigida. }\end{array}$ & 3 & 360 \\
\hline & & & $\begin{array}{l}\text { Utilização } \\
\text { inadequada de } \\
\text { equipamentos }\end{array}$ & 3 & Sem controle & 2 & $\begin{array}{l}\text { Incentivar a utilização } \\
\text { correta de equipamentos; } \\
\text { monitorar a utilização de } \\
\text { equipamentos. }\end{array}$ & 6 & 108 \\
\hline
\end{tabular}

Fonte: Dados dos autores, 2013. 
O Quadro 6 apresenta o resultado da avaliação no ambiente salas dos professores/ NUDE. Fonte: Dados dos autores, 2013.

Quadro 6. Ambiente: salas dos professores / NUDE

\begin{tabular}{|c|c|c|c|c|c|c|c|c|c|}
\hline $\begin{array}{l}\text { Aspecto } \\
\text { ambiental }\end{array}$ & $\begin{array}{l}\text { Impacto } \\
\text { ambiental }\end{array}$ & G & Causa potencial & $\mathrm{O}$ & Controle atual & D & Ação recomendada & $\mathbf{F}$ & IRA \\
\hline \multirow{2}{*}{$\begin{array}{l}\text { Geração de } \\
\text { resíduos }\end{array}$} & \multirow{2}{*}{$\begin{array}{l}\text { Reduz a pos- } \\
\text { sibilidade de } \\
\text { reciclagem, e/ou } \\
\text { reutilização. }\end{array}$} & 3 & $\begin{array}{l}\text { Falha no sistema de } \\
\text { coleta seletiva }\end{array}$ & 10 & $\begin{array}{l}\text { Monitoramento } \\
\text { visual }\end{array}$ & 1 & $\begin{array}{l}\text { Melhorar o controle; } \\
\text { aumentar a quantidade } \\
\text { de lixeiras e melhor } \\
\text { identificá-las. }\end{array}$ & 5 & 150 \\
\hline & & & $\begin{array}{l}\text { Falta de conscientiza- } \\
\text { ção dos usuários }\end{array}$ & 10 & $\begin{array}{l}\text { Monitoramento } \\
\text { visual }\end{array}$ & 4 & $\begin{array}{l}\text { Ações de educação } \\
\text { ambiental e conscien- } \\
\text { tização. }\end{array}$ & 6 & 720 \\
\hline \multirow{8}{*}{$\begin{array}{l}\text { Condições do } \\
\text { ambiente }\end{array}$} & \multirow{8}{*}{$\begin{array}{l}\text { Comprometi- } \\
\text { mento da saúde, } \\
\text { bem-estar e } \\
\text { segurança dos } \\
\text { usuários. }\end{array}$} & \multirow{8}{*}{6} & Limpeza insuficiente & 5 & $\begin{array}{l}\text { Monitoramento } \\
\text { visual }\end{array}$ & 1 & $\begin{array}{l}\text { Aperfeiçoar a progra- } \\
\text { mação das equipes de } \\
\text { limpeza; aumentar o } \\
\text { número de trabalha- } \\
\text { dores. }\end{array}$ & 9 & 270 \\
\hline & & & \multirow{2}{*}{$\begin{array}{l}\text { Ventilação inade- } \\
\text { quada }\end{array}$} & \multirow{2}{*}{10} & \multirow{2}{*}{ Conforto térmico } & \multirow{2}{*}{4} & $\begin{array}{c}\text { Ajustar a capacidade } \\
\text { em função do código } \\
\text { de edificações. }\end{array}$ & 3 & 720 \\
\hline & & & & & & & $\begin{array}{l}\text { Instalação de condicio- } \\
\text { nadores de ar e exaus- } \\
\text { tores. }\end{array}$ & 3 & 720 \\
\hline & & & $\begin{array}{l}\text { Iluminação inade- } \\
\text { quada }\end{array}$ & 10 & $\begin{array}{l}\text { Monitoramento } \\
\text { visual }\end{array}$ & 4 & $\begin{array}{l}\text { Redimensionamento } \\
\text { dos pontos de ilumina- } \\
\text { ção; verificação periódi- } \\
\text { ca; substituição. }\end{array}$ & 3 & 720 \\
\hline & & & $\begin{array}{l}\text { Iluminação de emer- } \\
\text { gência inoperante }\end{array}$ & 10 & $\begin{array}{l}\text { Monitoramento } \\
\text { visual }\end{array}$ & 2 & $\begin{array}{l}\text { Adequar ao ppci; visto- } \\
\text { ria visual periódica. }\end{array}$ & 3 & 360 \\
\hline & & & Acessibilidade & 4 & $\begin{array}{l}\text { Pouca ou nenhu- } \\
\text { ma }\end{array}$ & 2 & $\begin{array}{l}\text { Adaptação das depen- } \\
\text { dências para um me- } \\
\text { lhor atendimento. }\end{array}$ & 2 & 96 \\
\hline & & & Falha no layout & 7 & $\begin{array}{l}\text { Monitoramento } \\
\text { visual }\end{array}$ & 2 & $\begin{array}{c}\text { Melhorar a distribuição } \\
\text { do mobiliário; orga- } \\
\text { nizar cabos e fios dos } \\
\text { computadores }\end{array}$ & 7 & 588 \\
\hline & & & $\begin{array}{l}\text { Depósito inadequado } \\
\text { de material }\end{array}$ & 10 & $\begin{array}{l}\text { Monitoramento } \\
\text { visual }\end{array}$ & 4 & $\begin{array}{c}\text { Providenciar depósito } \\
\text { adequado para mate- } \\
\text { riais diversos liberando } \\
\text { o ambiente para o fim a } \\
\text { que se destina. }\end{array}$ & 3 & 720 \\
\hline Bens de con- & $\begin{array}{l}\text { Comprometi- } \\
\text { mento de re- }\end{array}$ & 3 & Consumo excessivo & 5 & $\begin{array}{l}\text { Controle de } \\
\text { estoque }\end{array}$ & 2 & $\begin{array}{l}\text { Estabelecimento de } \\
\text { processo de distribui- } \\
\text { ção de materiais; }\end{array}$ & 6 & 180 \\
\hline & $\begin{array}{l}\text { geração de resí- } \\
\text { duos }\end{array}$ & & $\begin{array}{l}\text { Pouca conscienti- } \\
\text { zação }\end{array}$ & 2 & Sem controle & 4 & $\begin{array}{l}\text { Conscientização do uso } \\
\text { racional dos materiais. }\end{array}$ & 8 & 192 \\
\hline \multirow{3}{*}{$\begin{array}{l}\text { Consumo de } \\
\text { energia }\end{array}$} & \multirow{3}{*}{$\begin{array}{l}\text { Redução dos } \\
\text { recursos naturais }\end{array}$} & \multirow{3}{*}{3} & $\begin{array}{l}\text { Falta de manutenção } \\
\text { no sistema }\end{array}$ & 10 & Sem controle & 4 & $\begin{array}{l}\text { Implantar plano pre- } \\
\text { ventivo de manutenção. }\end{array}$ & 7 & 840 \\
\hline & & & $\begin{array}{l}\text { Dimensionamento } \\
\text { inadequado }\end{array}$ & 10 & Sem controle & 4 & $\begin{array}{l}\text { Avaliação do projeto } \\
\text { elétrico e adequação à } \\
\text { demanda exigida. }\end{array}$ & 3 & 360 \\
\hline & & & $\begin{array}{l}\text { Utilização inadequa- } \\
\text { da de equipamentos }\end{array}$ & 3 & Sem controle & 2 & $\begin{array}{l}\text { Incentivar a utilização } \\
\text { correta de equipamen- } \\
\text { tos; monitorar a utiliza- } \\
\text { ção de equipamentos }\end{array}$ & 6 & 108 \\
\hline
\end{tabular}

O Quadro 6 apresenta os resultados obtidos da análise do ambiente salas dos professores/Sala do Núcleo de Desenvolvimento Educacional (NUDE). Verificou-se que nestes ambientes o IRA também indicou como prioridade o aspecto ambiental "consumo de energia" cujo valor obtido foi 840 , tendo como causa potencial a falta de manutenção no sistema e a ação recomendada foi implantar um plano preventivo de manutenção. 
O Quadro 7 se refere a análise do ambiente hall e corredores.

Quadro 7. Ambiente: hall e corredores

\begin{tabular}{|c|c|c|c|c|c|c|c|c|c|}
\hline $\begin{array}{l}\text { Aspecto } \\
\text { ambiental }\end{array}$ & $\begin{array}{l}\text { Impacto } \\
\text { ambiental }\end{array}$ & G & Causa potencial & $\mathrm{O}$ & Controle atual & D & Ação recomendada & $\mathbf{F}$ & IRA \\
\hline \multirow{3}{*}{$\begin{array}{l}\text { Consumo } \\
\text { de energia }\end{array}$} & \multirow{3}{*}{$\begin{array}{l}\text { Redução } \\
\text { dos recursos } \\
\text { naturais }\end{array}$} & \multirow{3}{*}{3} & $\begin{array}{c}\text { Falta de } \\
\text { manutenção no } \\
\text { sistema }\end{array}$ & 10 & Sem controle & 4 & $\begin{array}{l}\text { Implantar plano } \\
\text { preventivo de } \\
\text { manutenção. }\end{array}$ & 7 & 840 \\
\hline & & & $\begin{array}{l}\text { Dimensionamento } \\
\text { inadequado }\end{array}$ & 10 & Sem controle & 4 & $\begin{array}{l}\text { Avaliação do projeto } \\
\text { elétrico e adequação à } \\
\text { demanda exigida. }\end{array}$ & 3 & 360 \\
\hline & & & $\begin{array}{c}\text { Utilização } \\
\text { inadequada de } \\
\text { equipamentos }\end{array}$ & 3 & Sem controle & 2 & $\begin{array}{c}\text { Incentivar a } \\
\text { utilização correta } \\
\text { de equipamentos; } \\
\text { monitorar a utilização } \\
\text { de equipamentos. }\end{array}$ & 6 & 108 \\
\hline \multirow{5}{*}{$\begin{array}{l}\text { Condições } \\
\text { do ambiente }\end{array}$} & \multirow{5}{*}{$\begin{array}{l}\text { Compro- } \\
\text { metimento } \\
\text { da saúde, } \\
\text { bem-estar e } \\
\text { segurança dos } \\
\text { usuários }\end{array}$} & \multirow{5}{*}{6} & $\begin{array}{l}\text { Ventilação } \\
\text { inadequada }\end{array}$ & 10 & $\begin{array}{l}\text { Conforto } \\
\text { térmico }\end{array}$ & 4 & $\begin{array}{c}\text { Ajustar a capacidade } \\
\text { em função do código } \\
\text { de edificações. }\end{array}$ & 3 & 720 \\
\hline & & & $\begin{array}{l}\text { Extintores de } \\
\text { incêndio } \\
\text { inoperantes e/ou } \\
\text { inexistente. }\end{array}$ & 10 & $\begin{array}{l}\text { Monitoramento } \\
\text { visual }\end{array}$ & 2 & $\begin{array}{c}\text { Adequar ao ppci; } \\
\text { vistoria visual } \\
\text { periódica. }\end{array}$ & 3 & 360 \\
\hline & & & $\begin{array}{l}\text { Iluminação de } \\
\text { emergência } \\
\text { inoperante e/ou } \\
\text { inexistente. }\end{array}$ & 10 & $\begin{array}{c}\text { Monitoramento } \\
\text { visual }\end{array}$ & 2 & $\begin{array}{c}\text { Adequar ao ppci; } \\
\text { vistoria visual } \\
\text { periódica. }\end{array}$ & 3 & 360 \\
\hline & & & Acessibilidade & 4 & $\begin{array}{l}\text { Pouca ou } \\
\text { nenhuma }\end{array}$ & 2 & $\begin{array}{l}\text { Adaptação das } \\
\text { dependências para um } \\
\text { melhor atendimento. }\end{array}$ & 2 & 96 \\
\hline & & & $\begin{array}{l}\text { Depósito } \\
\text { inadequado de } \\
\text { material }\end{array}$ & 10 & $\begin{array}{c}\text { Monitoramento } \\
\text { visual }\end{array}$ & 4 & $\begin{array}{c}\text { Providenciar depó- } \\
\text { sito adequado para } \\
\text { materiais diversos } \\
\text { liberando o ambiente } \\
\text { para o fim a que se } \\
\text { destina. }\end{array}$ & 3 & 720 \\
\hline \multirow{2}{*}{$\begin{array}{l}\text { Geração de } \\
\text { resíduos }\end{array}$} & \multirow{2}{*}{$\begin{array}{c}\text { Reduz a } \\
\text { possibilidade } \\
\text { de } \\
\text { reciclagem, } \\
\text { e/ou } \\
\text { reutilização. }\end{array}$} & \multirow{2}{*}{3} & $\begin{array}{l}\text { Falha no sistema } \\
\text { de coleta seletiva }\end{array}$ & 10 & $\begin{array}{c}\text { Monitoramento } \\
\text { visual }\end{array}$ & 1 & $\begin{array}{l}\text { Melhorar o controle; } \\
\text { aumentar a } \\
\text { quantidade de lixeiras } \\
\text { e melhor identificá-las. }\end{array}$ & 5 & 150 \\
\hline & & & $\begin{array}{l}\text { Falta de conscienti- } \\
\text { zação dos usuários }\end{array}$ & 10 & $\begin{array}{c}\text { Monitoramento } \\
\text { visual }\end{array}$ & 4 & $\begin{array}{l}\text { Ações de educação } \\
\text { ambiental e } \\
\text { conscientização. }\end{array}$ & 6 & 720 \\
\hline
\end{tabular}

Fonte: Dados dos autores, 2013. 
Os resultados obtidos no ambiente Hall e corredores (Quadro 7) corroboram com os encontrados no Quadro 5 e 6 e apontaram como prioridade o aspecto ambiental "consumo de energia" cujo valor obtido foi 840 , tendo como causa potencial a falta de manutenção no sistema e a ação recomendada foi implantar um plano preventivo de manutenção.

O Quadro 8 contem as informações relativas ao ambiente banheiros.

Quadro 8. Ambiente: banheiros

\begin{tabular}{|c|c|c|c|c|c|c|c|c|c|}
\hline $\begin{array}{l}\text { Aspecto } \\
\text { ambiental }\end{array}$ & $\begin{array}{l}\text { Impacto } \\
\text { ambiental }\end{array}$ & G & $\begin{array}{c}\text { Causa } \\
\text { potencial }\end{array}$ & $\mathrm{O}$ & Controle atual & D & Ação recomendada & $\mathbf{F}$ & IRA \\
\hline $\begin{array}{l}\text { Consumo de } \\
\text { energia }\end{array}$ & $\begin{array}{l}\text { Redução } \\
\text { dos recursos } \\
\text { naturais }\end{array}$ & 3 & $\begin{array}{c}\text { Uso } \\
\text { inadequado }\end{array}$ & 2 & $\begin{array}{l}\text { Monitoramen- } \\
\text { to visual }\end{array}$ & 2 & $\begin{array}{l}\text { Substituição de lâmpa- } \\
\text { das incandescentes por } \\
\text { lâmpadas de maior } \\
\text { eficiência energética; } \\
\text { instalação de sensores de } \\
\text { movimento }\end{array}$ & 7 & 840 \\
\hline Odores & Desconforto & 3 & $\begin{array}{l}\text { Ventilação } \\
\text { insuficiente }\end{array}$ & 4 & $\begin{array}{l}\text { Controle olfa- } \\
\text { tivo }\end{array}$ & 1 & Instalação de exaustores & 3 & 36 \\
\hline \multirow[t]{2}{*}{$\begin{array}{l}\text { Bens de } \\
\text { consumo }\end{array}$} & \multirow{2}{*}{$\begin{array}{l}\text { Comprome- } \\
\text { timento de } \\
\text { recursos } \\
\text { naturais; } \\
\text { geração de } \\
\text { resíduos }\end{array}$} & \multirow[t]{2}{*}{3} & $\begin{array}{l}\text { Consumo } \\
\text { excessivo }\end{array}$ & 5 & $\begin{array}{l}\text { Controle de } \\
\text { estoque }\end{array}$ & 2 & $\begin{array}{c}\text { Estabelecimento de } \\
\text { processo de distribuição } \\
\text { de materiais; }\end{array}$ & 6 & 180 \\
\hline & & & $\begin{array}{c}\text { Pouca } \\
\text { conscientização }\end{array}$ & 2 & $\begin{array}{l}\text { Sem } \\
\text { controle }\end{array}$ & 4 & $\begin{array}{l}\text { Conscientização do uso } \\
\text { racional dos materiais. }\end{array}$ & 8 & 192 \\
\hline \multirow{2}{*}{$\begin{array}{l}\text { Consumo de } \\
\text { água }\end{array}$} & \multirow{2}{*}{$\begin{array}{l}\text { Redução dos } \\
\text { recursos na- } \\
\text { turais }\end{array}$} & \multirow{2}{*}{6} & $\begin{array}{l}\text { Utilização } \\
\text { inapropriada }\end{array}$ & 2 & $\begin{array}{l}\text { Monitoramen- } \\
\text { to visual }\end{array}$ & 2 & $\begin{array}{c}\text { Instalação de acionadores } \\
\text { automáticos }\end{array}$ & 3 & 72 \\
\hline & & & Vazamentos & 4 & $\begin{array}{l}\text { Monitoramen- } \\
\text { to visual }\end{array}$ & 1 & $\begin{array}{c}\text { Implantar plano periódico } \\
\text { de manutenção }\end{array}$ & 3 & 72 \\
\hline $\begin{array}{l}\text { Geração de } \\
\text { resíduos }\end{array}$ & $\begin{array}{l}\text { Poluição vi- } \\
\text { sual; compro- } \\
\text { metimento da } \\
\text { saúde e bem } \\
\text { estar. }\end{array}$ & 5 & $\begin{array}{l}\text { Pouca freqüên- } \\
\text { cia no recolhi- } \\
\text { mento }\end{array}$ & 5 & $\begin{array}{l}\text { Monitoramen- } \\
\text { to visual }\end{array}$ & 2 & $\begin{array}{l}\text { Aperfeiçoar a programa- } \\
\text { ção das equipes de limpe- } \\
\text { za; aumentar o número de } \\
\text { trabalhadores em função } \\
\text { da demanda }\end{array}$ & 3 & 150 \\
\hline $\begin{array}{l}\text { Depósito } \\
\text { inadequado } \\
\text { de material }\end{array}$ & $\begin{array}{l}\text { Poluição } \\
\text { visual; } \\
\text { ineficiência }\end{array}$ & 6 & $\begin{array}{l}\text { Espaço físico } \\
\text { insuficiente }\end{array}$ & 10 & $\begin{array}{l}\text { Monitoramen- } \\
\text { to visual }\end{array}$ & 4 & $\begin{array}{c}\text { Providenciar depósito } \\
\text { adequado para materiais } \\
\text { diversos liberando o am- } \\
\text { biente para o fim a que se } \\
\text { destina. }\end{array}$ & 3 & 720 \\
\hline
\end{tabular}

Fonte: Dados dos autores, 2013.

Os resultados obtidos no ambiente banheiros (Quadro 8) mostraram como prioridade o aspecto ambiental "consumo de energia" cujo valor obtido foi 840 , tendo como causa potencial o uso inadequado e a ação recomendada foi a substituição de lâmpadas incandescentes por lâmpadas de maior eficiência energética e a instalação de sensores de movimento.

Os Quadros 9 e 10 apresentam informações relativas respectivamente aos ambientes secretaria acadêmica/administrativa e laboratórios. 
Quadro 9. Ambiente: secretaria acadêmica / administrativa

\begin{tabular}{|c|c|c|c|c|c|c|c|c|c|}
\hline $\begin{array}{l}\text { Aspecto } \\
\text { ambiental }\end{array}$ & $\begin{array}{l}\text { Impacto } \\
\text { ambiental }\end{array}$ & G & Causa potencial & $\mathrm{O}$ & Controle atual & D & Ação recomendada & F & IRA \\
\hline \multirow{2}{*}{$\begin{array}{l}\text { Geração de } \\
\text { resíduos }\end{array}$} & \multirow{2}{*}{$\begin{array}{l}\text { Reduz a } \\
\text { possibili- } \\
\text { dade de } \\
\text { reciclagem, } \\
\text { e/ou reutili- } \\
\text { zação. }\end{array}$} & \multirow[t]{2}{*}{3} & $\begin{array}{l}\text { Falha no sistema } \\
\text { de coleta seletiva }\end{array}$ & 10 & $\begin{array}{c}\text { Monitoramento } \\
\text { visual }\end{array}$ & 1 & $\begin{array}{l}\text { Melhorar o controle; } \\
\text { aumentar a quantida- } \\
\text { de de lixeiras e melhor } \\
\text { identificá-las. }\end{array}$ & 5 & 150 \\
\hline & & & $\begin{array}{c}\text { Falta de } \\
\text { conscientização } \\
\text { dos usuários }\end{array}$ & 10 & $\begin{array}{c}\text { Monitoramento } \\
\text { visual }\end{array}$ & 4 & $\begin{array}{l}\text { Ações de educação } \\
\text { ambiental e } \\
\text { conscientização. }\end{array}$ & 6 & 720 \\
\hline \multirow{9}{*}{$\begin{array}{l}\text { Condições } \\
\text { do am- } \\
\text { biente }\end{array}$} & \multirow{9}{*}{$\begin{array}{l}\text { Comprome- } \\
\text { ti-mento da } \\
\text { saúde, bem } \\
\text {-estar e se- } \\
\text { gurança dos } \\
\text { usuários. }\end{array}$} & \multirow{9}{*}{6} & $\begin{array}{c}\text { Limpeza } \\
\text { insuficiente }\end{array}$ & 5 & $\begin{array}{c}\text { Monitoramento } \\
\text { visual }\end{array}$ & 1 & $\begin{array}{l}\text { Aperfeiçoar a progra- } \\
\text { mação das equipes de } \\
\text { limpeza; aumentar o } \\
\text { número de trabalhadores. }\end{array}$ & 9 & 270 \\
\hline & & & \multirow{2}{*}{$\begin{array}{l}\text { Ventilação } \\
\text { inadequada }\end{array}$} & \multirow[t]{2}{*}{10} & \multirow{2}{*}{$\begin{array}{l}\text { Conforto } \\
\text { térmico }\end{array}$} & \multirow[t]{2}{*}{4} & $\begin{array}{l}\text { Ajustar a capacidade } \\
\text { em função do código de } \\
\text { edificações. }\end{array}$ & 3 & 720 \\
\hline & & & & & & & $\begin{array}{l}\text { Instalação de condiciona- } \\
\text { dores de ar e exaustores. }\end{array}$ & 3 & 720 \\
\hline & & & $\begin{array}{l}\text { Iluminação } \\
\text { inadequada }\end{array}$ & 10 & $\begin{array}{c}\text { Monitoramento } \\
\text { visual }\end{array}$ & 4 & $\begin{array}{l}\text { Redimensionamento dos } \\
\text { pontos de iluminação; } \\
\text { verificação periódica; } \\
\text { substituição. }\end{array}$ & 3 & 720 \\
\hline & & & $\begin{array}{l}\text { Extintores de in- } \\
\text { cêndio inoperantes }\end{array}$ & 10 & $\begin{array}{c}\text { Monitoramento } \\
\text { visual }\end{array}$ & 2 & $\begin{array}{l}\text { Adequar ao ppci; vistoria } \\
\text { visual periódica. }\end{array}$ & 3 & 360 \\
\hline & & & $\begin{array}{l}\text { Iluminação de } \\
\text { emergência } \\
\text { inoperante }\end{array}$ & 10 & $\begin{array}{c}\text { Monitoramento } \\
\text { visual }\end{array}$ & 2 & $\begin{array}{l}\text { Adequar ao ppci; vistoria } \\
\text { visual periódica. }\end{array}$ & 3 & 360 \\
\hline & & & Ruídos externos & 10 & $\begin{array}{l}\text { Monitoramento } \\
\text { auditivo }\end{array}$ & 4 & $\begin{array}{c}\text { Adaptação das } \\
\text { dependências para } \\
\text { supressão dos ruídos. }\end{array}$ & 2 & 480 \\
\hline & & & Acessibilidade & 4 & $\begin{array}{l}\text { Pouca ou } \\
\text { nenhuma }\end{array}$ & 2 & $\begin{array}{c}\text { Adaptação das } \\
\text { dependências para um } \\
\text { melhor atendimento. }\end{array}$ & 2 & 96 \\
\hline & & & $\begin{array}{l}\text { Depósito inade- } \\
\text { quado de material }\end{array}$ & 10 & $\begin{array}{l}\text { Monitoramento } \\
\text { visual }\end{array}$ & 4 & $\begin{array}{c}\text { Providenciar depósito } \\
\text { adequado. }\end{array}$ & 3 & 720 \\
\hline \multirow{2}{*}{$\begin{array}{l}\text { Bens de } \\
\text { consumo }\end{array}$} & \multirow{2}{*}{$\begin{array}{l}\text { Compro- } \\
\text { metimento } \\
\text { de recursos } \\
\text { naturais; } \\
\text { geração de } \\
\text { resíduos }\end{array}$} & \multirow{2}{*}{3} & $\begin{array}{l}\text { Consumo } \\
\text { excessivo }\end{array}$ & 5 & $\begin{array}{l}\text { Controle de } \\
\text { estoque }\end{array}$ & 2 & $\begin{array}{c}\text { Estabelecimento de } \\
\text { processo de distribuição } \\
\text { de materiais; }\end{array}$ & 6 & 180 \\
\hline & & & $\begin{array}{c}\text { Pouca } \\
\text { conscientização }\end{array}$ & 2 & Sem controle & 4 & $\begin{array}{l}\text { Conscientização do uso } \\
\text { racional dos materiais. }\end{array}$ & 8 & 192 \\
\hline \multirow{3}{*}{$\begin{array}{l}\text { Consumo } \\
\text { de energia }\end{array}$} & \multirow{3}{*}{$\begin{array}{l}\text { Redução } \\
\quad \text { dos } \\
\text { recursos } \\
\text { naturais }\end{array}$} & \multirow{3}{*}{3} & $\begin{array}{c}\text { Falta de } \\
\text { manutenção no } \\
\text { sistema }\end{array}$ & 10 & Sem controle & 4 & $\begin{array}{l}\text { Implantar plano } \\
\text { preventivo de } \\
\text { manutenção. }\end{array}$ & 7 & 840 \\
\hline & & & $\begin{array}{l}\text { Dimensionamento } \\
\text { inadequado }\end{array}$ & 10 & Sem controle & 4 & $\begin{array}{c}\text { Avaliação do projeto } \\
\text { elétrico e adequação à } \\
\text { demanda exigida. }\end{array}$ & 3 & 360 \\
\hline & & & $\begin{array}{l}\text { Utilização } \\
\text { inadequada de } \\
\text { equipamentos }\end{array}$ & 3 & Sem controle & 2 & $\begin{array}{c}\text { Incentivar a utilização } \\
\text { correta de equipamentos; } \\
\text { monitorar a utilização de } \\
\text { equipamentos. }\end{array}$ & 6 & 108 \\
\hline
\end{tabular}

Fonte: Dados dos autores, 2013. 
Os Quadros 9 e 10 também indicaram como prioridade o aspecto ambiental "consumo de energia" cujos valores obtidos foram 840 , tendo como causa potencial a falta de manutenção no sistema e a ação recomendada de implantar um plano preventivo de manutenção.

Quadro 10. Ambiente: laboratórios

\begin{tabular}{|c|c|c|c|c|c|c|c|c|c|}
\hline $\begin{array}{l}\text { Aspecto } \\
\text { ambiental }\end{array}$ & $\begin{array}{l}\text { Impacto } \\
\text { ambiental }\end{array}$ & G & $\begin{array}{l}\text { Causa poten- } \\
\text { cial }\end{array}$ & $\mathrm{O}$ & Controle atual & D & Ação recomendada & F & IRA \\
\hline \multirow{2}{*}{$\begin{array}{l}\text { Geração de } \\
\text { resíduos }\end{array}$} & \multirow{2}{*}{$\begin{array}{l}\text { Reduz a } \\
\text { possibilida- } \\
\text { de de reci- } \\
\text { clagem, e/ou } \\
\text { reutilização. }\end{array}$} & \multirow{2}{*}{3} & $\begin{array}{c}\text { Falha no } \\
\text { sistema de } \\
\text { coleta seletiva }\end{array}$ & 10 & $\begin{array}{l}\text { Monitoramento } \\
\text { visual }\end{array}$ & 1 & $\begin{array}{c}\text { Melhorar o controle; } \\
\text { aumentar a quantida- } \\
\text { de de lixeiras e melhor } \\
\text { identificá-las. }\end{array}$ & 5 & 150 \\
\hline & & & $\begin{array}{c}\text { Falta de } \\
\text { conscientização } \\
\text { dos usuários }\end{array}$ & 10 & $\begin{array}{l}\text { Monitoramento } \\
\text { visual }\end{array}$ & 4 & $\begin{array}{l}\text { Ações de educação } \\
\text { ambiental e } \\
\text { conscientização. }\end{array}$ & 6 & 720 \\
\hline \multirow{2}{*}{$\begin{array}{l}\text { Dispersão } \\
\text { de resíduos } \\
\text { perigosos }\end{array}$} & \multirow{2}{*}{$\begin{array}{l}\text { Contamina- } \\
\text { ções diversas }\end{array}$} & \multirow[b]{2}{*}{8} & $\begin{array}{l}\text { Desatenção do } \\
\text { usuário }\end{array}$ & 3 & Sem controle & 4 & $\begin{array}{c}\text { Prática constante dos } \\
\text { procedimentos básicos de } \\
\text { utilização. }\end{array}$ & 6 & 576 \\
\hline & & & $\begin{array}{l}\text { Treinamento } \\
\text { inadequado ou } \\
\text { inexistente }\end{array}$ & 3 & Sem controle & 2 & $\begin{array}{l}\text { Implantar treinamento } \\
\text { rotineiro, bem como } \\
\text { normas de procedimentos } \\
\text { padrões. }\end{array}$ & 5 & 240 \\
\hline \multirow{10}{*}{$\begin{array}{l}\text { Condições } \\
\text { do } \\
\text { ambiente }\end{array}$} & \multirow{10}{*}{$\begin{array}{l}\text { Compro- } \\
\text { metimento } \\
\text { da saúde, } \\
\text { bem-estar e } \\
\text { segurança } \\
\text { dos usuários. }\end{array}$} & \multirow{10}{*}{6} & $\begin{array}{l}\text { Limpeza } \\
\text { insuficiente }\end{array}$ & 5 & $\begin{array}{l}\text { Monitoramento } \\
\text { visual }\end{array}$ & 1 & $\begin{array}{l}\text { Aperfeiçoar a progra- } \\
\text { mação das equipes de } \\
\text { limpeza; aumentar o nú- } \\
\text { mero de trabalhadores. }\end{array}$ & 9 & 270 \\
\hline & & & \multirow{2}{*}{$\begin{array}{l}\text { Ventilação } \\
\text { inadequada }\end{array}$} & \multirow[t]{2}{*}{10} & \multirow{2}{*}{$\begin{array}{l}\text { Conforto } \\
\text { térmico }\end{array}$} & \multirow[t]{2}{*}{4} & $\begin{array}{l}\text { Ajustar a capacidade } \\
\text { em função do código de } \\
\text { edificações. }\end{array}$ & 3 & 720 \\
\hline & & & & & & & $\begin{array}{l}\text { Instalação de condiciona- } \\
\text { dores de ar e exaustores. }\end{array}$ & 3 & 720 \\
\hline & & & $\begin{array}{l}\text { Iluminação } \\
\text { inadequada }\end{array}$ & 10 & $\begin{array}{l}\text { Monitoramento } \\
\text { visual }\end{array}$ & 4 & $\begin{array}{l}\text { Redimensionamento dos } \\
\text { pontos de iluminação; } \\
\text { verificação periódica; } \\
\text { substituição. }\end{array}$ & 3 & 720 \\
\hline & & & $\begin{array}{l}\text { Extintores } \\
\text { de incêndio } \\
\text { inoperantes }\end{array}$ & 10 & $\begin{array}{l}\text { Monitoramento } \\
\text { visual }\end{array}$ & 2 & $\begin{array}{l}\text { Adequar ao ppci; vistoria } \\
\text { visual periódica. }\end{array}$ & 3 & 360 \\
\hline & & & $\begin{array}{l}\text { Iluminação de } \\
\text { emergếncia } \\
\text { inoperante }\end{array}$ & 10 & $\begin{array}{l}\text { Monitoramento } \\
\text { visual }\end{array}$ & 2 & $\begin{array}{l}\text { Adequar ao ppci; vistoria } \\
\text { visual periódica. }\end{array}$ & 3 & 360 \\
\hline & & & Acessibilidade & 4 & $\begin{array}{l}\text { Pouca ou } \\
\text { nenhuma }\end{array}$ & 2 & $\begin{array}{l}\text { Adaptação das } \\
\text { dependências para um } \\
\text { melhor atendimento. }\end{array}$ & 2 & 96 \\
\hline & & & $\begin{array}{l}\text { Utilização ina- } \\
\text { dequada de } \\
\text { equipamentos } \\
\text { elétricos diver- } \\
\text { sos }\end{array}$ & 6 & $\begin{array}{c}\text { Monitoramento } \\
\text { visual }\end{array}$ & 4 & $\begin{array}{l}\text { Levantamento de carga e } \\
\text { adequação dos circuitos; } \\
\text { instalação de tomadas } \\
\text { individualizadas; proibi- } \\
\text { ção da utilização de “Ts" } \\
\text { e/ou extensões; monitorar } \\
\text { a utilização de equipa- } \\
\text { mentos periodicamente; } \\
\text { conscientizar usuários. }\end{array}$ & 5 & 720 \\
\hline & & & $\begin{array}{l}\text { Acesso sem } \\
\text { os devidos } \\
\text { equipamentos } \\
\text { individuais de } \\
\text { proteção }\end{array}$ & 9 & $\begin{array}{l}\text { Monitoramento } \\
\text { visual }\end{array}$ & 2 & $\begin{array}{l}\text { Conscientização dos } \\
\text { usuários; determinar con- } \\
\text { trole de acesso restrito. }\end{array}$ & 6 & 648 \\
\hline & & & $\begin{array}{l}\text { Depósito ina- } \\
\text { dequado de } \\
\text { material }\end{array}$ & 10 & $\begin{array}{l}\text { Monitora-men- } \\
\text { to visual }\end{array}$ & 4 & $\begin{array}{c}\text { Providenciar depósito } \\
\text { adequado. }\end{array}$ & 3 & 720 \\
\hline
\end{tabular}


Quadro 10. continuação...

\begin{tabular}{|c|c|c|c|c|c|c|c|c|c|}
\hline $\begin{array}{l}\text { Aspecto } \\
\text { ambiental }\end{array}$ & $\begin{array}{l}\text { Impacto } \\
\text { ambiental }\end{array}$ & G & $\begin{array}{l}\text { Causa poten- } \\
\text { cial }\end{array}$ & $\mathrm{O}$ & Controle atual & D & Ação recomendada & $\mathbf{F}$ & IRA \\
\hline \multirow{2}{*}{$\begin{array}{l}\text { Bens de } \\
\text { consumo }\end{array}$} & \multirow{2}{*}{$\begin{array}{l}\text { Comprome- } \\
\text { ti-mento de } \\
\text { recursos natu- } \\
\text { rais; geração } \\
\text { de resíduos }\end{array}$} & \multirow{2}{*}{3} & $\begin{array}{l}\text { Consumo } \\
\text { excessivo }\end{array}$ & 5 & $\begin{array}{l}\text { Controle de } \\
\text { estoque }\end{array}$ & 2 & $\begin{array}{l}\text { Estabelecimento de processo } \\
\text { de distribuição de materiais; }\end{array}$ & 6 & 180 \\
\hline & & & $\begin{array}{c}\text { Pouca } \\
\text { conscientização }\end{array}$ & 2 & Sem controle & 4 & $\begin{array}{l}\text { Conscientização do uso ra- } \\
\text { cional dos materiais. }\end{array}$ & 8 & 192 \\
\hline \multirow{3}{*}{$\begin{array}{l}\text { Consumo de } \\
\text { energia }\end{array}$} & \multirow{3}{*}{$\begin{array}{l}\text { Redução dos } \\
\text { recursos na- } \\
\text { turais }\end{array}$} & \multirow{3}{*}{3} & $\begin{array}{l}\text { Falta de } \\
\text { manutenção no } \\
\text { sistema }\end{array}$ & 10 & Sem controle & 4 & $\begin{array}{l}\text { Implantar plano preventivo } \\
\text { de manutenção. }\end{array}$ & 7 & 840 \\
\hline & & & $\begin{array}{l}\text { Dimensionamen- } \\
\text { to inadequado }\end{array}$ & 10 & Sem controle & 4 & $\begin{array}{l}\text { Avaliação do projeto elétrico } \\
\text { e adequação à demanda } \\
\text { exigida. }\end{array}$ & 3 & 360 \\
\hline & & & $\begin{array}{l}\text { Utilização } \\
\text { inadequada de } \\
\text { equipamentos }\end{array}$ & 3 & Sem controle & 2 & $\begin{array}{l}\text { Incentivar a utilização correta } \\
\text { de equipamentos; monitorar } \\
\text { a utilização de equipamentos. }\end{array}$ & 6 & 108 \\
\hline
\end{tabular}

Fonte: Dados dos autores, 2013.

Após a análise dos dados, foi possível constatar que a falta de manutenção do sistema elétrico representa o principal fator que tem contribuído para elevar os impactos ambientais negativos dos locais estudados.

\section{CONCLUSÕES}

A análise FMEA é uma metodologia que serve para avaliar e minimizar riscos por meio da análise das possíveis falhas e programar ações mais eficazes.

Os resultados mostram-se bastante promissores quanto à possibilidade de implantação de ações corretivas ou preventivas em função dos aspectos e impactos ambientais encontrados. Da mesma forma, verificou-se a plena possibilidade de que os resultados contribuam para posterior implantação do SGA.

Com a determinação dos Índices de Riscos Ambientais (IRAs) é possível definir um calendário de execução das ações recomendadas, com base na graduação dos riscos ambientais obtidos.

Por fim, através dos levantamentos realizados pode-se verificar que ações de baixo custo e retorno imediato poderão ser implementadas reduzindo em curto prazo o Índice de Risco Ambiental.

\section{REFERÊNCIAS}

ANDRADE, M. R. S.; TURRIONI, J. B. Uma Metodologia de análise dos aspectos e impactos ambientais através da utilização do FMEA. ENEGEP, USP/POLI, São Paulo, 2000.

VANDENBRANDE, W. W. How to use FMEA to reduce the size of your quality toolbox; Quality Progress. v.31, n.11, p.97-100, 1998.

CAMPANI, D. B. Implementação do sistema de gestão ambiental no prédio da engenharia mecância-UFRGS. XXX Congresso Interamericano de Ingeniería Sanitaria Y Ambiental, Punta Del Este, 2006.

TAUCHEN, J.;BRANDLI, L. L. A gestão ambiental em instituições de ensino superior: modelo para implantação em campus universitário. Gestão \& Produção, v.13, n.3, p.503-515, 2006.

ZAMBRANO, T.F.; MARTINS, M.F. Utilização do método FMEA para avaliação do risco ambiental. Revista Gestão \&Produção, v. 14, n. 2, p. 295-309, 2007. 